\title{
REVIEW
}

\section{Clinical review: Canadian National Advisory Committee on Blood and Blood Products - Massive Transfusion Consensus Conference 2011: report of the panel}

\author{
Walter H Dzik*, Morris A Blajchman²,3, Dean Fergusson ${ }^{4}$, Morad Hameed $^{5}$, Blair Henry ${ }^{6}$, Andrew W Kirkpatrick7, \\ Teresa Korogy ${ }^{8}$, Sarvesh Logsetty ${ }^{9}$, Robert C Skeate ${ }^{10}$, Simon Stanworth" ${ }^{11}$, Charles MacAdams ${ }^{12+}$ and Brian Muirhead ${ }^{13+}$
}

\begin{abstract}
In June 2011 the Canadian National Advisory Committee on Blood and Blood Products sponsored an international consensus conference on transfusion and trauma. A panel of 10 experts and two external advisors reviewed the current medical literature and information presented at the conference by invited international speakers and attendees. The Consensus Panel addressed six specific questions on the topic of blood transfusion in trauma. The questions focused on: ratio-based blood resuscitation in trauma patients; the impact of survivorship bias in current research conclusions; the value of nonplasma coagulation products; the role of protocols for delivery of urgent transfusion; the merits of traditional laboratory monitoring compared with measures of clot viscoelasticity; and opportunities for future research. Key findings include a lack of evidence to support the use of 1:1:1 blood component ratios as the standard of care, the importance of early use of tranexamic acid, the expected value of an organized response plan, and the recommendation for an integrated approach that includes antifibrinolytics, rapid release of red blood cells, and a foundation ratio of blood components adjusted by results from either traditional coagulation tests or clot viscoelasticity or both. The present report is intended to provide guidance to practitioners, hospitals, and policy-makers.
\end{abstract}

tExternal advisors

*Corresponding author: sdzik@partners.org

'Blood Transfusion Service, Massachusetts General Hospital, 55 Fruit Street, Boston, MA 02114, USA

Full list of author information is available at the end of the article

\section{Introduction}

Brutal and unexpected, serious injury is a health tragedy sparing no age group. In many countries, including Canada, trauma is the leading cause of death between the ages of 1 and 44, a leading cause of death at all ages, and the leading cause of potential years of life lost [1]. During the past 20 years, advances in many areas of trauma systems, resuscitation, surgical therapies, and critical care support have improved the odds of surviving serious traumatic injury [2]. Among the many possible contributing factors to improved survival is the availability of large-volume transfusion support and improved understanding of trauma-related defects in hemostasis. These contributions have led to critical questions deserving well-performed clinical trials [3]. Recent transfusion management of severely injured military personnel has heightened expectations for the role of blood component therapy in improving patient outcomes [4,5], but evidence supporting the application of these changes to civilian healthcare has not been established and marked variation in practice exists. Transfusion support for trauma patients experiencing hemorrhage greater than one blood volume has not been optimized [6,7].

In June 2011 the Canadian National Advisory Committee on Blood and Blood Products sponsored a 3-day consensus conference, during which a field of international leaders presented data focused on six specific questions pertinent to trauma and transfusion support. The six questions were posted for public review prior to the conference and attendees were encouraged to participate in the proceedings. A multidisciplinary Consensus Panel of experts was tasked with weighing information found in the recently published literature and presented at the conference. The panel was composed of three trauma surgeons, two hematologists, two anesthesiologists, two regional blood center medical directors, one trauma nurse, one ethicist, and one clinical trials design expert. Presentations are listed online by the National 
Advisory Committee on Blood and Blood Products [8]. A summary of the Proceedings of the Consensus Conference, including synopses of the public presentations of each speaker, will be published separately.

Each question posed to the panel was discussed in faceto-face meetings conducted during the 3-day conference. Panel members had access to the presentations of the speakers. Each panel member had an equal voice. For each response created by the panel, the degree of consensus was noted with a minimum requirement of $70 \%$ agreement required for consensus. Strong consensus required $>90 \%$ agreement. Any concern or objection raised by a panel member was included in the report. The panel considered issues of patient equity and access to healthcare services in Canada, but was not asked to address blood support of trauma in neonates or small children. Pediatric trauma thus represents an important area for future consensus. The Consensus Conference Panel's response to each of the six key questions follows.

\section{Question 1. Formula-driven resuscitation as the standard of care: is there sufficient evidence to justify 1:1:1 formula-driven resuscitation as the standard of care for bleeding trauma patients?}

The panel reviewed the quality and generalizability of current evidence; methodological challenges in existing reports; risk-benefit balance; cost-benefit balance; alternatives to 1:1:1 ratio-driven resuscitation; and equity and access for Canadians. Currently, evidence for benefit is limited to retrospective and historical control-case series with no prospective randomized trials addressing ratio-based blood support. Retrospective, nonrandomized, or not properly controlled analyses comparing survival and other outcomes among patients who have received different ratios of blood components determined post hoc have significant flaws in methodology [9]. There is no high-quality information to form a confident assessment of the risk-benefit ratio surrounding ratio-driven blood resuscitation applied prospectively to cohorts of patients at risk for massive hemorrhage. There are no costeffectiveness studies on this subject. There is insufficient investigation of the potential for an increased rate of adverse outcomes following formula-driven resuscitation, especially among patients who ultimately do not require massive blood transfusion. Application of a 1:1:1 blood component strategy in the absence of clear benefit will place demands on blood inventories with potential negative consequences for nontrauma patients. Alternatives to a formula-driven blood resuscitation strategy exist.

\section{Recommendation of the Consensus Panel}

As a result of the above considerations, especially the limited scientific evidence, the panel concluded that 1:1:1 formula-driven care cannot be recommended as a national standard of care for Canada. Practice recommendations for transfusion support are offered in the Discussion. See Figure 1.

Panel consensus: unanimous agreement.

Question 1a. To what extent is the evidence on 1:1:1 formula-driven resuscitation affected by survivorship bias? Question 1a.i. What is the magnitude of the problem of survivorship bias?

Question 1a.ii. What are the options to correct the bias?

Each study of formula-driven resuscitation reviewed by the panel was found to be susceptible to survivorship bias [10]. Two reports that attempted to correct for survivorship bias by treating the blood component ratio as a time-dependent covariate [11,12] found no benefit on mortality. The relationship between blood ratios and survival rates is not linear [13,14], although reported comparisons may have assumed linearity. Moreover, current studies of ratio-driven blood support are further complicated by other sources of bias, including those commonly found in retrospective studies, registry studies, and studies without random allocation. These methodologic concerns include secular trends, poor generalizability of single-site studies, selection bias, and imbalance of measured and unmeasured confounders [9].

Failure to adequately address survivorship bias is a serious impediment to the interpretation of retrospective studies of blood ratios and has probably contributed substantially to the observed interpretation and uptake of results. It is unlikely that further retrospective studies will overcome survivorship bias or resolve questions regarding the value of ratio-driven resuscitation.

While treating blood ratios as a time-dependent covariate may improve analysis, this analytic approach assumes that the risk of mortality is constant over the period of observation. Exclusion of early deaths from analysis, while partially accounting for survivorship bias, excludes the key subpopulation with the highest, and perhaps modifiable, mortality. Randomized controlled trials will require a very large sample size in order to demonstrate any statistically significant effect. In the absence of randomized controlled trials, better organized observational studies in which the exact timing of blood infusions is captured may allow analysis that partially corrects for survivorship bias. Studies based on a cluster randomized trial design or a before-after design would have the advantage that each participating site need only follow one protocol.

Panel consensus: unanimous agreement. 


\section{Early (up-front) administration of tranexamic acid ( 1 gram over 10}

minutes and then infusion of 1 gram over 8 hours) as soon as possible and preferably within 3 hours of injury.

2. For patients with critical bleeding, immediate application of a 'foundation ratio' of blood components. An example of such a foundation ratio is 6 RBCs and 3 FFP for the initial treatment.

3. Adjustments to the foundation ratio of transfusion support based on the clinical course and results of laboratory tests using goal-directed blood therapy. For example, platelet transfusions can be added if the patient's count is $<100,000 / \mu \mathrm{l}$ (or projected to be soon $<100,000 / \mu \mathrm{l}$ ) or if the $\mathrm{TEG}^{\mathrm{TM}} /$ ROTEM $^{\mathrm{TM}}$ maximum amplitude is below the local threshold for therapy. The specific laboratory tests used and the target goals of therapy can be locally determined emphasizing the value of tests with rapid turnaround time.

Figure 1. Three-strategy approach to transfusion support in trauma patients at risk for massive hemorrhage. FFP, fresh frozen plasma; RBC, red blood cell; TEG $^{\text {TM }} /$ ROTEM $^{\text {TM }}$, thromboelastography/rotational thromboelastometry.

\section{Question 2. In addition to plasma, is there a role for other blood components and products in the resuscitation of massively bleeding patients?} Question 2a. What is the role for goal-directed or formuladriven platelet transfusion, fibrinogen use, cryoprecipitate transfusion, fibrinogen concentrate and factor XIII, prothrombin complex and activated recombinant factor VII and tranexamic acid?

Because adequate tissue oxygenation is essential for survival in massively bleeding patients, the first principle of blood resuscitation remains the re-establishment of an adequate blood volume and cardiac output, and the optimization of oxygen-carrying capacity. Platelet transfusions are of presumed benefit for trauma patients with thrombocytopenia, but there is no evidence of benefit for nonthrombocytopenic patients who have taken antiplatelet agents. Hypofibrinoginemia occurs in some patients with massive bleeding, and when present should be treated. There are insufficient data, however, to support the routine use of cryoprecipitate or fibrinogen concentrate in patients with fibrinogen levels $>150 \mathrm{mg} / \mathrm{dl}$ [15].

There is evidence from more than one randomized controlled trial to support the lack of utility with the use of recombinant activated factor VII (rVIIa) for the treatment of bleeding in blunt trauma or penetrating trauma patients [16-18]. rVIIa is not licensed for nor recommended for the prevention or management of hemorrhage in trauma patients. In contrast, a large randomized controlled trial has supported the use of tranexamic acid in trauma patients, especially if given in the first 3 hours after injury $[19,20]$.
Topical control of bleeding sites - including ligature or resection, endovascular occlusion, packing with or without topical hemostatics, electrocautery, and proximal tourniquets - is expected to have the highest benefit-torisk ratio of any hemostasis therapy. Nevertheless, there is insufficient information regarding the benefit of topical application of blood components (for example, cryoprecipitate, fibrin sealants) or topical pharmacologic agents (for example, antifibrinolytics, collagen) to make definitive recommendations.

Panel consensus: unanimous agreement.

\section{Question 3. Beyond trauma: going beyond trauma - what is the level of evidence and biological rationale supporting the adoption of 1:1:1 formula-driven resuscitation in cardiac surgery and other specialties?}

Two retrospective studies, conducted in patients undergoing abdominal aortic aneurysm surgery, examined outcomes related to blood transfusion ratios [21,22]. No studies have specifically addressed the use of ratio-driven blood resuscitation in cardiovascular surgery, upper gastrointestinal bleeding, burn surgery, liver transplantation, or obstetrical bleeding. These patients have comorbidities, clinical features, and hemostatic disorders very different from those of trauma patients. Moreover, toxicities resulting from the high volume of blood components that are given in 1:1:1 blood resuscitation protocols may be different in nontrauma patients compared with trauma patients. 
Recommendation of the Consensus Panel

Overall, the literature for ratio-driven blood resuscitation applied to nontrauma patients is insufficient to recommend that this transfusion support strategy be directly applied to nontrauma patients with major bleeding.

Panel consensus: unanimous agreement.

\section{Question 4. Limitations of massive transfusion protocols: what are the practical limitations of massive transfusion protocols?}

Question 4a. Should all hospitals in Canada have massive transfusion protocols? Question $4 \mathrm{~b}$. What are the logistical challenges to the blood bank and blood inventory; clinicians and laboratory to have massive transfusion protocols?

There is evidence that clinical pathways in healthcare tend to improve the consistency and quality of care [23], and it is widely expected that a predetermined plan for transfusion support of trauma patients with critical bleeding will improve patient outcomes [24]. However, evidence that such plans improve patient outcomes is based on a limited number of before-after studies [25-29].

Activation of urgent and large-volume transfusion plans are meant to focus attention on the critically ill patient. These plans can divert attention away from other patients, however, and unnecessary activation of massive transfusion plans may adversely affect the care of other patients. Development of a working policy for treatment of life-threatening massive hemorrhage is challenging, and survey data suggest there is wide variability of practice $[7,30]$. Challenges and practical considerations are listed in Table 1.

\section{Recommendation of the Consensus Panel}

Despite these significant challenges, the panel recommended that all hospitals in Canada that supply blood transfusion services should have a local procedure in place for urgent blood transfusion. The details of the procedure should be formulated in the context of locally available resources at the facility. Smaller hospitals should be encouraged to participate in regional or provincial trauma systems, to optimize local resources, to establish criteria for referral of care, and to establish pathways for communication and expeditious transfer for definitive trauma care.

Panel consensus: strong agreement.
Question 5. Usefulness of laboratory tests: what do coagulation laboratory tests help (or not help) in massively bleeding patients?

Question 5a. What do thromboelastography and rotational thromboelastometry add to the management of massive hemorrhage? Question 5b. What are the strategies to reduce the turnaround time for laboratory results to allow for goal-directed resuscitation?

Although hemodilution remains a concern during prolonged trauma resuscitation, recent evidence suggests that the acute coagulopathy of trauma is not related to dilution of clotting factors. Rather, the acute coagulopathy of trauma is related to activation of a systemic injury response, including release of tissue-type plasminogen activator with conversion of plasminogen to plasmin, and systemic endothelial activation leading to activation of protein C [31-34]. This pathophysiologic model might suggest a potential disadvantage to early administration of fresh frozen plasma, which provides an infusion of plasminogen and protein $C$, both substrates for anticoagulant pathways. More research is needed to distinguish causes, rather than markers, of coagulopathy. As already noted in patients with severe head trauma [35], treatments will be ineffective if directed at abnormal coagulation tests that are only markers of association and not the cause of adverse outcomes.

\section{Traditional laboratory testing}

Serial measurements of a limited number of traditional laboratory tests (hemoglobin, platelet count, prothrombin time/International Normalized Ratio, fibrinogen, ionized $\mathrm{Ca}^{2+}, \mathrm{pH}$, and electrolytes), if made available with a turnaround time that allows them to reflect the clinical situation, are a useful adjunct to the clinical assessment of bleeding in patients undergoing massive transfusion $[36,37]$. The turnaround time for selected tests can be substantially shortened by attention to the processing details and policies [36]. Although point-of-care, wholeblood coagulation tests offer promise, results for the prothrombin time/International Normalized Ratio and fibrinogen may be dependent on the hematocrit and difficult to standardize for samples with abnormal values [38]. Key factors that need to be considered in the execution of traditional laboratory tests with rapid turnaround time are listed in Table 2.

\section{Assays of clot viscoelasticity (thromboelastography and rotational thromboelastometry)}

Coagulation testing based on clot viscoelasticity represents an alternative to traditional laboratory coagulation testing [39-42]. Thromboelastography $\left(\mathrm{TEG}^{\mathrm{m}}\right)$ and rotational thromboelastometry $\left(\right.$ ROTEM $\left.^{\mathrm{TM}}\right)$ add a direct display of clot strength and subsequent clot lysis not observed with traditional laboratory testing [43-45]. 


\section{Table 1. Developing a preparedness plan for trauma and critical bleeding}

Challenges

- $\quad$ Access to high-quality science upon which to design a transfusion policy. Clinical studies are needed to rapidly and reliably predict which patients will need large-volume transfusion support; and to evaluate laboratory-guided versus ratio-based transfusion.

- Access to resources needed for creating, implementing, monitoring, and updating the protocol.

- Access to information technology resources needed to execute rapid, large-volume transfusion.

- $\quad$ Access to resources required to train and educate a wide variety of staff including physicians, nurses, operating room and blood bank staff, and administrators. Ongoing training is needed especially in areas where trauma care is not a routine occurrence.

- Access to equipment required for delivery of urgent large-volume transfusion.

- Access to sufficient blood supply. Smaller hospitals may not be able to stock sufficient blood for large-volume resuscitation. The distance from the regional supplier may cause depletion of local blood stocks and threaten appropriate blood support of other patients. Transfusion policies that assign $\mathrm{O}$-negative red blood cells and $A B$ plasma to trauma patients may deplete regional reserves of these uncommon blood groups.

- Governance/agreement between multiple parties with different perspectives. Policies need hospital executive support and agreement by a variety of stakeholders from different departments. Clinicians involved in policy-making need a systems perspective in addition to that representing individual patient care.

Practical considerations

- Communication between the clinical team, the blood bank, the laboratory, and treatment locations (emergency room, operating room, interventional radiology suite, and so forth) of critical stages in the patient's treatment.

- $\quad$ Rapid assessment of patients who are at risk for critical bleeding.

- Efficient and useful mechanisms for notification of key hospital services required for delivery of urgent transfusion support.

- $\quad$ Proper patient and specimen identification for unconscious patients.

- Adequate large-bore catheter venous access.

- Early administration of antifibrinolytic agents.

- Policy for immediate release of uncrossmatched red blood cells.

- Rapid delivery of a properly labeled patient sample for $\mathrm{ABO} / \mathrm{Rh}$.

- Policy for waiving restrictions on special blood component attributes (for example, irradiated blood or cytomegalovirus-seronegative blood).

- Organized, sequential delivery of additional red blood cells, fresh frozen plasma, and platelets to the patient's location.

- Laboratory, nursing, and messenger staff allocations.

- Rapid turnaround systems for laboratory testing of hematology, coagulation, and critical metabolic parameters.

- Plan for inventory restocking with regional blood supplier.

- $\quad$ Development of predefined guidelines on when to withdraw support.

Process improvement

- Inclusion of all relevant participants including nonclinical participants (for example, porter services, managers of equipment and supply).

- $\quad$ Practice runs that simulate as much as possible actual trauma events.

- Periodic process review, critique, and change.

- Data collection including blood product wastage, especially O-negative red blood cells and AB plasma.

- Periodic assessment of spillover effects upon nontrauma patients whose transfusion care is altered as a consequence of the policy used to support trauma patients with critical bleeding.

Experience in trauma patients has identified specific parameters of $\mathrm{TEG}^{\mathrm{TM}}$ and ROTEM $^{\mathrm{TM}}$ that can be used as a guide to blood component treatment [41,46-48]. In trauma patients, however, results correlated poorly $\left(r^{2}=\right.$ 0.22 to 0.28 ) with those obtained using traditional laboratory tests [49]. Moreover, a Cochrane review found lack of evidence that transfusion guided by $\mathrm{TEG}^{\mathrm{TM}}$ or by ROTEM $^{\mathrm{TM}}$ improved morbidity or mortality in patients with severe bleeding [50]. Point-of-care testing introduces challenges of standardization, quality control, and staffing, especially in programs with less frequent trauma cases.

\section{Recommendation of the Consensus Panel}

There have been no substantial direct comparisons of clinical outcomes in a cohort of patients randomized to receive resuscitation guided by TEG $^{\mathrm{TM}}$ or ROTEM ${ }^{\mathrm{TM}}$ versus traditional testing. For example, although both traditional laboratory coagulation tests and tests of clot viscoelasticity can be used to determine fibrinogen levels, published data are not sufficient to decide whether clinical outcomes are improved by using one method versus another as a guide to fibrinogen replacement. Either traditional laboratory tests or tests based on clot viscoelasticity, or combinations of these tests, despite their 
limitations, can provide serial information for the initiation and ongoing blood component therapy and resuscitation in massive hemorrhage due to trauma. There is currently insufficient evidence to favor either approach to laboratory testing.

Panel consensus: unanimous agreement.

\section{Question 6. Future research: what research is needed to improve the outcome of massively bleeding trauma patients and the use of blood and blood products?}

The term 'massive transfusion' has several shortcomings, including: defining a medical condition by its treatment; treating a continuous variable (red blood cells (RBCs) transfused) as if it was dichotomous; and fostering retrospective analyses. Because of its limitations, the Consensus Panel felt that the continued use of the term 'massive transfusion' should be discouraged except to describe an outcome of clinically important bleeding.

The term 'acute coagulopathy of trauma' requires better definition using laboratory tests that reflect the underlying physiology, have useful predictive performance characteristics, and are reproducible across different institutions. New risk-scoring systems that would include physiologic markers associated with the acute coagulopathy of trauma would also be welcome.

Clinical studies on transfusion support in trauma need to be hypothesis driven with clearly defined interventions, defined populations for study, meaningful outcomes, specific capture of treatment-related toxicities, and a sufficient follow-up period. Study designs will need to address the difficult challenges of patient selection, consent, enrollment, randomization, treatment masking, sample size, data collection, and adverse event capture and reporting [16].

\section{Panel recommendations}

The panel identified five categories of specific research opportunity in the topic of trauma, critical bleeding, and transfusion (see Table 3). Finally, the panel noted that better research on healthcare cost is needed for all categories of trauma-related blood component resuscitation. Analysis of proposed treatment strategies can consider cost-effectiveness and cost utility, and can perform sensitivity analyses to better understand the key drivers of cost to the national healthcare system. Considerations of cost are essential to balance societal investment in both the treatment of trauma and the prevention of injury.

\section{Discussion and panel recommendations}

The Consensus Conference process has several important strengths, including full public access to the process, broad participation, and a goal of reasonable consensus based on the current evidence. The consensus process generates an opinion based on presented evidence and with consideration of equity and access to patients in both rural and urban settings. The panel was selected with a goal of broad independent representation. The panel did not formulate the questions and had no influence on the content presented at the meeting.

The Consensus Conference process also has weaknesses. The panel was not asked to conduct a formal systematic review of the literature or to provide a grading of the quality of prior published literature. The views of the panel therefore represent expert independent opinion.

\section{Prevention of trauma is cost-effective}

There can be little doubt that many injury-prevention measures, already implemented, are more cost-effective than the treatment of trauma; and this fact should weigh heavily on decisions regarding allocation of government funding to promote wider acceptance of prevention programs [51,52]. Despite prevention efforts, injuries related to motor vehicles [53], self-inflicted trauma including suicide [54], and use of alcohol or drugs [53,55] remain common preventable causes of injury. Opportunities thus remain for further reduction of serious injury and death from motor vehicle accidents, falls, and trauma related to firearms, alcohol and drug abuse, and depression.

Only a very small percentage of trauma patients can have survival directly affected by changes to current transfusion strategies

The great majority of trauma victims do not experience massive hemorrhage. Among fatally injured patients 40 


\section{Table 3. Specific research opportunities in the field of trauma, critical bleeding, and transfusion}

Strategies for blood resuscitation of trauma patients with critical bleeding

- Prospective randomized head-to-head comparison trials of goal-directed, ratio only, or combination strategies for blood support in trauma patients.

- Immune consequences of exposure to large quantities of incompatible group A and group B soluble antigens found in ABO-compatible but nonidentical plasma.

- $\quad$ Prospective randomized studies that examine effects of colloid versus crystalloid resuscitation.

- Studies of clinical hemostatic efficacy and adverse effects of stored thawed plasma compared with plasma thawed within 24 hours, including the efficacy and adverse effects on nontrauma patients who might receive such products.

Other blood therapies

- $\quad$ Studies comparing triggers for fibrinogen supplementation, different sources of fibrinogen, and methods to monitor effect of transfusion of fibrinogencontaining products.

- Preclinical studies of the effect of novel inhibitors of the protein C pathway on the acute coagulopathy of trauma.

Conditions other than trauma

- Identification of features common to all patients receiving sustained high rates of transfusion as well as research designed to identify clinical, laboratory, and treatment features unique to critical bleeding in trauma, cardiac surgery, obstetrics, and pediatrics.

Clinical pathways for delivery of transfusion support in trauma complicated by critical bleeding

- Studies of the value effect of massive transfusion protocols.

- Studies addressing the difficulty and the process of withdrawing therapy among patients with negligible physiologic chance of survival.

- $\quad$ Studies of access to massive transfusion strategies in remote healthcare settings.

Coagulation testing and the acute coagulopathy of trauma

- Studies of the value of various specific laboratory tests to support the transfusion of massively bleeding trauma patients. These to include both classical tests of hemostasis and thromboelastography/rotational thromboelastometry testing.

- Well-designed, controlled investigation of topical hemostasis therapy including topical application of blood components and the topical application of procoagulant drugs/agents.

to $60 \%$ die at the scene or in transit, with higher fatality rates in rural settings [56-59]. A review of trauma fatalities from a Canadian level 1 trauma program found that $15 \%$ died from hemorrhage and that $16 \%$ of these deaths were deemed preventable [60]. Among the preventable deaths, the root cause was delayed recognition in hospital of bleeding rather than preventable death due to blood transfusion strategies. An additional 11\% died from a combination of bleeding and severe central nervous system injury where transfusion practice has less impact on overall survival. Similar estimates were found at another Canadian level 1 trauma center (RS Morad Hameed, personal communication, Vancouver General Hospital, 2011). If 40-60\% of trauma fatalities occur prior to admission to hospital, and if $15 \%$ of hospitalized trauma cases die from hemorrhage, then even if $20 \%$ of hospitalized trauma cases could be saved by alternative strategies of transfusion support, only $1 \%$ to $3 \%$ of all trauma fatalities could be directly addressed by changes in transfusion practice. Because some fatal bleeding outcomes result from extensive and uncorrectable anatomic injury, the percentage of preventable bleeding deaths that can be directly addressed by changes in blood transfusion practice is likely to be even lower.

These estimates are relevant to the importance of injury prevention, for considerations of the cost-effectiveness of transfusion strategies, and for determining the required size of prospective clinical trials focused on transfusion. When indiscriminately applied as part of a standard protocol, expensive transfusion interventions will not be cost-effective due to the small number of individuals who actually benefit from the intervention. Reducing prehospital deaths through injury prevention remains an area with high opportunity for saving lives. Nevertheless, for trauma patients who experience massive blood loss, hemorrhage is a common cause of death [61].

\section{Civilian trauma and military trauma are not the same}

Treatment of battle casualties represents an important area for the exploration of new treatments of trauma patients. Some aspects of trauma seen among soldiers and noncombatants wounded in theaters of war have similarities to trauma seen in civilian settings (for example, burns, gunshot wounds). However, substantial differences exist between civilian trauma and military trauma [62]. These differences include the characteristics of the underlying population, the nature of the trauma, and the treatments available. For example, 93\% of trauma in Canada is blunt trauma, with only $5 \%$ penetrating trauma and $2 \%$ burns [53]. In military trauma these proportions are reversed. The panel felt that observations, clinical reports, policies, and practice patterns obtained in and relevant to the theater of war, while of potential benefit to civilian healthcare [63], should not be 


\section{Table 4. Resources on trauma}

Public Health Agency of Canada

- Injury Surveillance On-Line

- Canadian Hospitals Injury Reporting and Prevention Program

Canadian Institute for Health Information (CIHI)

- $\quad \mathrm{CIHI}$ National Trauma Registry

- National Trauma Registry 2011 Report: Hospitalizations for Major Injury in Canada

Trauma Association of Canada

- Interdisciplinary Trauma Network of Canada

- Trauma Registry Information Specialists of Canada

- Accredited trauma centers

American College of Surgeons: Committee on Trauma

- Advanced trauma operative management

- International Association for Trauma Surgery and Intensive Care

- Definitive Surgical Trauma Care Courses

Trauma.org

- Definitive Surgical Trauma Care and Definitive Surgical Trauma Skills

Canadian Association of Emergency Physicians

National Advisory Committee on Blood and Blood Products

Blood Easy Handbook

Canadian Blood Services [http://www.phac-aspc.gc.ca/index-eng.php]

[http://dsol-smed.hc-sc.gc.ca/dsol-smed/is-sb/index-eng.php]

[http://www.phac-aspc.gc.ca/injury-bles/chirpp/index-eng.php]

[http://www.cihi.ca/CIHI-ext-portal/internet/EN/Home/home/cihi000001]

[http://secure.cihi.ca/cihiweb/products/NTR_CDS_2008_2009_Annual_Report.pdf]

[http://www.traumacanada.org/]

[http://www.facs.org/trauma/index.html]

[http://atomcourse.com/]

[http://www.latsic.org/index.html]

[http://www.iatsic.org/DSTC.html]

[http://www.trauma.org/index.php/]

[http://www.trauma.org/index.php/resources/general/definitive_surgical_trauma_care/]

[http://www.caep.ca/]

[http://www.nacblood.ca/]

[http://www.cas.ca/English/Page/Files/111_Bloody_Easy\%20Handbook\%202.pdf]

[http://www.transfusionmedicine.ca/resources/books/vein-vein/complications-bloodtransfusion] considered immediately transferrable to civilian trauma patients.

\section{Practice recommendations for transfusion support of critical bleeding in trauma patients}

Trauma care is complex, and outcomes depend on timing, the nature of the injury, patient age and comorbidities, geographic location and transport times, surgical and anesthesia expertise, intensive care services, physiologic and laboratory assessment, and transfusion support. Practitioners can find valuable information from several sources, listed in Table 4 and in recently published guidelines [64-66]. The initial approach to the care of the injured patient should be in keeping with current principles - such as those detailed in the Advanced Trauma Life Support guidelines, which are regularly updated $[67,68]$. Direct control of bleeding with definitive management by surgery or interventional radiology remains the mainstay of therapy. The most important step in the transfusion support of trauma patients is the development of a local, agreed-upon practice approach to blood support.

\section{Red blood cells and tissue oxygenation}

Tissue oxygenation remains the first goal of blood therapy. Because of the direct link between tissue ischemia, disordered hemostasis [31,69], and mortality, the most important blood component for prevention and treatment of coagulopathy is packed RBCs. Local policies should clearly provide for the rapid delivery of uncrossmatched RBCs. Life-saving RBC transfusion should not be delayed. Venous access of sufficient size for rapid blood infusion should be established without delay. Although higher concentrations of hemoglobin are associated with improved hemostasis [70], the optimal target hemoglobin concentration for patients undergoing resuscitation from traumatic injury is not well established. Intraoperative blood salvage, when selectively used for cases involving large-volume blood loss, can provide a ready source of ongoing erythrocyte support for trauma patients. Devices designed for rapid blood infusion and blood warming can facilitate transfusion support and can mitigate complications of hypothermia.

\section{Pharmacologic support of hemostasis}

A large multicenter prospective trial has established that early use of an antifibrinolytic (tranexamic acid) reduced overall mortality in trauma patients, especially if administered within 3 hours of injury $[19,20]$. The incremental cost of tranexamic acid per life-year gained was just \$64 [71]. In contrast, when tested in trauma trials, even multiple doses of rVIIa did not improve survival 
$[17,18]$ and may have worsened outcomes due to an increased risk of arterial thrombosis [72-74]. The lack of clinical effectiveness and the extremely high cost of rVIIa relative to RBCs translate into a negligible cost-effectiveness for rVIIa.

\section{Transfusion support of hemostasis}

The Consensus Panel felt that neither a strategy of transfusion support based solely on laboratory testing nor a strategy based solely on blood component ratios was demonstrated to result in optimal transfusion support for all trauma patients. A potential shortcoming of laboratorydirected therapy, as the only strategy for blood support in massive hemorrhage, is the potential to fall behind. This can result from reliance on assays with low sensitivity and predictive value for the hemostatic derangements among trauma patients, or from delays in test turnaround time. A potential short-coming of ratio-driven blood support, as the only strategy of transfusion care, is overtransfusion with plasma and platelets resulting either in no benefit $[75,76]$ or in added toxicity (especially pulmonary) [13,76-78]. The evidence supporting a 1:1:1 transfusion strategy in civilian trauma was not sufficiently strong to overcome concerns about its toxicity to patients, nor to recommend it as a standard of care in Canada. There was insufficient evidence to favor a panel of traditional tests over $\mathrm{TEG}^{\mathrm{TM}} / \mathrm{ROTEM}^{\mathrm{TM}}$ tests or vice versa for guiding therapy. There was also insufficient information to favor point-of-care testing versus centralized testing.

Because patients receiving large-volume transfusion support vary greatly in the nature and degree of injury, the panel wished to emphasize the importance of individual tailored therapy over rigid protocols of blood transfusion support. In addition, treatment guidelines appropriate for severe trauma patients do not apply to elective surgery patients who experience significant hemorrhage. Patients undergoing elective surgery without shock, acidosis, and significant tissue injury do not experience the same degree of hemostatic breakdown observed in severe trauma.

\section{Suggested blood component support of the critically bleeding trauma patient}

Given the current available knowledge, practical management of blood support for the trauma patient with critical bleeding should give consideration to a combination of up-front hemostatic support, a foundation ratio of blood component release, and goal-directed adjustment of transfusion therapy. A specific example of the combination of these three strategies - suitable for a definitive-treatment center and applied to patients who are identified as at high risk for massive hemorrhage - is shown in Figure 1.

\section{Platelet concentrates}

At the University of Maryland program, $<3 \%$ of patients with an Injury Severity Score $>15$ had an admission platelet count $<100,000 / \mu \mathrm{l}$ [79]. Thrombocytopenia will generally not develop until at least one blood volume of resuscitation has occurred. There is currently no highquality evidence to support the use of up-front platelet transfusions. These platelet transfusions do not reverse antiplatelet agents such as clopidogrel and there is no evidence to support use of platelet transfusions to improve outcomes in patients who have recently taken antiplatelet agents [80]. Retrospective studies in both trauma patients and nontrauma patients with intracranial hemorrhage have found no benefit from platelet transfusions given to patients who are taking antiplatelet agents [81-83].

\section{Fibrinogen}

Because a decline in fibrinogen concentration is seen in hyperfibrinolysis, consumption coagulopathy, disseminated intravascular coagulation, and hemodilution, and because a decline in fibrinogen is observed in massively injured patients, specific attention to fibrinogen may be of merit in transfusion support of critical bleeding [45]. Fresh frozen plasma and thawed plasma contain physiologic levels of fibrinogen. Higher concentrations of fibrinogen are found in cryoprecipitate and in fibrinogen concentrates. Current evidence does not support the superiority of one source of fibrinogen over another [15].

\section{Prothrombin complex concentrates}

Whether or not infusion of prothrombin complex concentrates used either as a substitute for plasma or as a supplement to plasma is safe or improves outcomes beyond that which would be observed without their use has not been adequately studied (a lack of data).

Transfusion and trauma care in both small, rural and large, urban healthcare facilities

Canadians residing in rural and remote locations have been shown to be at increased risk of sustaining severe injuries, and to have decreased access to definitive trauma care once injuries occur [58]. Despite the greater challenges to care, smaller hospitals not specializing in trauma can apply early treatments of proven value such as tranexamic acid. Because no single approach to transfusion support of trauma patients is of proven superiority, there is no requirement that specific practices regarding blood products be imposed as an absolute standard of care. Improved communication within existing regional trauma systems should provide valuable guidance for the initial care of critically injured patients and supports the principle of equitable delivery of care [84-87]. Large, urban hospitals offering level 1 trauma care have the 
opportunity to establish centers of excellence and use their vantage point to pursue, in a collaborative way, welldesigned prospective trials intended to answer specific questions regarding best practice in trauma.

\section{Abbreviations}

$\mathrm{RBC}$, red blood cell; ROTEM ${ }^{\mathrm{T}}$, rotational thromboelastometry; rVIla, recombinant activated factor VII; TEG ${ }^{\mathrm{TM}}$, thromboelastography.

\section{Competing interests}

AWK has served on an Advisory Panel discussing the use of ultrasound contrast media for Lantheus Medical Corp, Boston, MA, USA. WHD, MAB, $\mathrm{DF}, \mathrm{MH}, \mathrm{BH}, \mathrm{TK}, \mathrm{SL}, \mathrm{RS}, \mathrm{SS}, \mathrm{CM}$ and $\mathrm{BM}$ declare that they have no competing interests.

\section{Authors' information}

BM is Acting Vice-Chair of the National Advisory Committee on Blood and Blood Products. AWK is the immediate Past-President of the Trauma Association of Canada.

\section{Acknowledgements}

The Canadian National Advisory Committee on Blood and Blood Products provided funding. The authors wish to acknowledge the Planning Committee of the Massive Transfusion Consensus Conference who organized the meeting, formulated the questions to the panel, and invited the speakers who presented data at the meeting. The planning committee members were: Sandro Rizoli (chairman) (Sunnybrook Health Sciences Centre, Toronto, Canada); Jeannie Callum (Sunnybrook Health Sciences Centre, Toronto, Canada); Cheryl Doncaster (Department of Health and Community Services, Newfoundland and Labrador, Canada); David Howe (Canadian Blood Services, Ottawa, Canada); Catherine Moltzan (Winnipeg Regional Health Authority, Winnipeg, Canada); Susan Nahirniak (University of Alberta Hospital, Edmonton, Canada); Bartolomeu Nascimento (Sunnybrook Health Sciences Centre, Toronto, Canada); Katerina Pavenski (St Michael's Hospital, Toronto, Canada); Homer Tien (Sunnybrook Health Sciences Centre, Toronto, Canada); and Lucinda Whitman (Eastern Health, Newfoundland and Labrador, Canada).

\section{Author details}

'Blood Transfusion Service, Massachusetts General Hospital, 55 Fruit Street, Boston, MA 02114, USA. ${ }^{2}$ Canadian Blood Services, Southern Ontario Region, Departments of Pathology and Medicine, McMaster University Medical Centre, 1200 Main Street West, Hamilton, Ontario, Canada L8N 3Z5. ${ }^{3} \mathrm{NHLBI}$ TMH Clinical Trials Network, Bethesda, MD, USA. ${ }^{4}$ Department of Clinical Epidemiology, Ottawa Hospital Research Institute, Clinical Epidemiology Program, Faculty of Medicine, University of Ottawa, 6th Floor Critical Care Wing, Office W6119, 501 Smyth Road, Box 201, Ottawa, Ontario, Canada K1H 8L6. ${ }^{5}$ General Surgery Residency Program, Department of Surgery and Critical Care Medicine, University of British Columbia, Trauma Services, Vancouver General Hospital, 855 W 12 Avenue, Vancouver, British Columbia, Canada V5Z 1M9. ${ }^{6}$ Sunnybrook Health Sciences Centre, Joint Centre for Bioethics, Department of Family and Community Medicine, University of Toronto, Sunnybrook Health Sciences Centre, 2075 Bayview Avenue, Room H2-39, Toronto, Ontario, Canada M4N 3M5. 'Department of Critical Care Medicine and Surgery, University of Calgary, Regional Trauma Services, Foothills Medical Centre, 140329 St NW, Calgary, Alberta, Canada T2N 2T9. ${ }^{8}$ Emergency Department, Sunnybrook Health Sciences Center, 2075 Bayview Avenue, Toronto, Ontario, Canada M4N 3M5. 'Manitoba Firefighters'Burn Unit, University of Manitoba, GC401A, 820 Sherbrook Avenue, Winnipeg, Manitoba, Canada R3A1R9. ${ }^{10} \mathrm{C}$ anadian Blood Services Central Ontario Region, Department of Laboratory Medicine and Pathobiology, University of Toronto, 67 College Street, Toronto, Ontario, Canada M5G 2M1. " Department of Haematology, John Radcliffe Hospital, University of Oxford, UK. ${ }^{2}$ Perioperative Blood Conservation Program Calgary Zone, Department of Anesthesia, Foothills Medical Centre, $140329^{\text {th }}$ Street NW, Calgary, Alberta, Canada T2N 2T9. ${ }^{13}$ Transfusion Practices Committee, Blood Conservation Servcies, Winnipeg Regional Health Authority, Department of Anesthesiology, University of Manitoba, 347 Cambridge Street, Winnipeg, Manitoba, Canada R3M 3E8.

Published: 8 December 2011

\section{References}

1. Facts on Injury [http://www.phac-aspc.gc.ca/injury-bles/facts-eng.php]

2. Pfeifer R, Tarkin IS, Rocos B, Pape HC: Patterns of mortality and causes of death in polytrauma patients - has anything changed? Injury 2009, 40:907-911.

3. Josephson CD, Glynn SA, Kleinman SH, Blajchman MA: A multidisciplinary 'think tank': the top 10 clinical trial opportunities in transfusion medicine from the National Heart, Lung, and Blood Institute-sponsored 2009 stateof-the-science symposium. Transfusion 2011, 51:828-841.

4. Simmons JW, White CE, Eastridge BJ, Holcomb JB, Perkins JG, Mace JE, Blackbourne LH: Impact of improved combat casualty care on combat wounded undergoing exploratory laparotomy and massive transfusion. J Trauma 2011, 71:S82-S86.

5. Borgman MA, Spinella PC, Perkins JG, Grathwohl KW, Repine T, Beekley AC, Sebesta J, Jenkins D, Wade CE, Holcomb JB: The ratio of blood products transfused affects mortality in patients receiving massive transfusions at a combat support hospital. J Trauma 2007, 63:805-813.

6. Nascimento B, Callum J, Rubenfeld G, Neto JB, Lin Y, Rizoli S: Clinical review: Fresh frozen plasma in massive bleedings - more questions than answers. Crit Care 2010, 14:202.

7. Hoyt DB, Dutton RP, Hauser CJ, Hess JR, Holcomb JB, Kluger Y, Mackway-Jones K, Parr MJ, Rizoli SB, Yukioka T, Bouillon B: Management of coagulopathy in the patients with multiple injuries: results from an international survey of clinical practice. J Trauma 2008, 65:755-764; discussion 764-765.

8. National Advisory Committee on Blood and Blood Products [www.nacblood.ca]

9. Rajasekhar A, Gowing R, Zarychanski R, Arnold DM, Lim W, Crowther MA, Lottenberg R: Survival of trauma patients after massive red blood cell transfusion using a high or low red blood cell to plasma transfusion ratio. Crit Care Med 2011, 39:1507-1513.

10. Stansbury LG, Dutton RP, Stein DM, Bochicchio GV, Scalea TM, Hess JR: Controversy in trauma resuscitation: do ratios of plasma to red blood cells matter? Transfus Med Rev 2009, 23:255-265.

11. Snyder CW, Weinberg JA, McGwin G, Jr, Melton SM, George RL, Reiff DA, Cross JM, Hubbard-Brown J, Rue LW, 3rd, Kerby JD: The relationship of blood product ratio to mortality: survival benefit or survival bias? J Trauma 2009, 66:358-362; discussion 362-364.

12. Magnotti LJ, Zarzaur BL, Fischer PE, Williams RF, Myers AL, Bradburn EH, Fabian TC, Croce MA: Improved survival after hemostatic resuscitation: does the emperor have no clothes? J Trauma 2011, 70:97-102.

13. Plurad D, Martin M, Green D, Salim A, Inaba K, Belzberg H, Demetriades D, Rhee $P$ : The decreasing incidence of late posttraumatic acute respiratory distress syndrome: the potential role of lung protective ventilation and conservative transfusion practice. J Trauma 2007, 63:1-7; discussion 8.

14. Acosta JA, Yang JC, Winchell RJ, Simons RK, Fortlage DA, HollingsworthFridlund P, Hoyt DB: Lethal injuries and time to death in a level I trauma center. J Am Coll Surg 1998, 186:528-533.

15. Meyer MA, Ostrowski SR, Windelov NA, Johansson PI: Fibrinogen concentrates for bleeding trauma patients: what is the evidence? Vox Sang 2011, 101:185-190.

16. Curry N, Hopewell S, Doree C, Hyde C, Brohi K, Stanworth S: The acute management of trauma hemorrhage: a systematic review of randomized controlled trials. Crit Care 2011, 15:R92.

17. Boffard KD, Riou B, Warren B, Choong PI, Rizoli S, Rossaint R, Axelsen M, Kluger $Y$ : Recombinant factor VIla as adjunctive therapy for bleeding control in severely injured trauma patients: two parallel randomized, placebocontrolled, double-blind clinical trials. J Trauma 2005, 59:8-15; discussion 15-18.

18. Hauser CJ, Boffard K, Dutton R, Bernard GR, Croce MA, Holcomb JB, Leppaniemi A, Parr M, Vincent JL, Tortella BJ, Dimsits J, Bouillon B; CONTROL Study Group: Results of the CONTROL trial: efficacy and safety of recombinant activated factor VII in the management of refractory traumatic hemorrhage. J Trauma 2010, 69:489-500.

19. CRASH-2 trial collaborators, Shakur H, Roberts I, Bautista R, Caballero J, Coats T, Dewan Y, El-Sayed H, Gogichaishvili T, Gupta S, Herrera J, Hunt B, Iribhogbe P, Izurieta M, Khamis H, Komolafe E, Marrero MA, Mejía-Mantilla J, Miranda J, Morales C, Olaomi O, Olldashi F, Perel P, Peto R, Ramana PV, Ravi RR, Yutthakasemsunt S: Effects of tranexamic acid on death, vascular occlusive events, and blood transfusion in trauma patients with significant haemorrhage (CRASH-2): a randomised, placebo-controlled trial. Lancet 2010, 376:23-32. 
20. CRASH-2 collaborators, Roberts I, Shakur H, Afolabi A, Brohi K, Coats T, Dewan Y, Gando S, Guyatt G, Hunt BJ, Morales C, Perel P, Prieto-Merino D, Woolley T: The importance of early treatment with tranexamic acid in bleeding trauma patients: an exploratory analysis of the CRASH-2 randomised controlled trial. Lancet 2011, 377:1096-1101, e1091-e1092.

21. Johansson PI, Stensballe J, Rosenberg I, Hilslov TL, Jorgensen L, Secher NH: Proactive administration of platelets and plasma for patients with a ruptured abdominal aortic aneurysm: evaluating a change in transfusion practice. Transfusion 2007, 47:593-598.

22. Mell MW, O'Neil AS, Callcut RA, Acher CW, Hoch JR, Tefera G, Turnipseed WD: Effect of early plasma transfusion on mortality in patients with ruptured abdominal aortic aneurysm. Surgery 2010, 148:955-962.

23. Rotter T, Kinsman L, James E, Machotta A, Gothe H, Willis J, Snow P, Kugler J: Clinical pathways: effects on professional practice, patient outcomes, length of stay and hospital costs. Cochrane Database Syst Rev 2010 3:CD006632.

24. National Patient Safety Agency: Rapid response report NPSA/2010/017: The transfusion of blood and blood components in an emergency. UK: National Health Service; 2010 [http://www.nrls.npsa.nhs.uk/resources/?entryid45=836 $59 \& p=4]$.

25. O'Keeffe T, Refaai M, Tchorz K, Forestner JE, Sarode R: A massive transfusion protocol to decrease blood component use and costs. Arch Surg 2008 143:686-690; discussion 690-691.

26. Riskin DJ, Tsai TC, Riskin L, Hernandez-Boussard T, Purtill M, Maggio PM, Spain DA, Brundage SI: Massive transfusion protocols: the role of aggressive resuscitation versus product ratio in mortality reduction. J Am Coll Surg 2009, 209:198-205

27. Cotton BA, Au BK, Nunez TC, Gunter OL, Robertson AM, Young PP: Predefined massive transfusion protocols are associated with a reduction in organ failure and postinjury complications. J Trauma 2009, 66:41-48; discussion 48-49.

28. Cotton BA, Dossett LA, Au BK, Nunez TC, Robertson AM, Young PP: Room for (performance) improvement: provider-related factors associated with poor outcomes in massive transfusion. J Trauma 2009, 67:1004-1012.

29. Dente CJ, Shaz BH, Nicholas JM, Harris RS, Wyrzykowski AD, Patel S, Shah A, Vercruysse GA, Feliciano DV, Rozycki GS, Salomone JP, Ingram WL: Improvements in early mortality and coagulopathy are sustained better in patients with blunt trauma after institution of a massive transfusion protocol in a civilian level I trauma center. J Trauma 2009, 66:1616-1624

30. Schuster KM, Davis KA, Lui FY, Maerz LL, Kaplan LJ: The status of massive transfusion protocols in United States trauma centers: massive transfusion or massive confusion? Transfusion 2010, 50:1545-1551.

31. Hess JR, Brohi K, Dutton RP, Hauser CJ, Holcomb JB, Kluger Y, Mackway-Jones K, Parr MJ, Rizoli SB, Yukioka T, Hoyt DB, Bouillon B: The coagulopathy of trauma: a review of mechanisms. J Trauma 2008, 65:748-754.

32. Brohi K, Cohen MJ, Ganter MT, Schultz MJ, Levi M, Mackersie RC, Pittet JF: Acute coagulopathy of trauma: hypoperfusion induces systemic anticoagulation and hyperfibrinolysis. J Trauma 2008, 64:1211-1217 discussion 1217.

33. Kashuk JL, Moore EE, Sawyer M, Wohlauer M, Pezold M, Barnett C, Biffl WL, Burlew CC, Johnson JL, Sauaia A: Primary fibrinolysis is integral in the pathogenesis of the acute coagulopathy of trauma. Ann Surg 2010, 252:434-442; discussion 443-444.

34. Curry N, Stanworth S, Hopewell S, Doree C, Brohi K, Hyde C: Trauma-induced coagulopathy - a review of the systematic reviews: is there sufficient evidence to guide clinical transfusion practice? Transfus Med Rev 2011, 25:217-231, e212

35. Talving P, Lustenberger T, Lam L, Inaba K, Kobayashi L, Barmparas G, Branco $B C$, Demetriades D: Early coagulopathy after isolated severe traumatic brain injury: relationship with hypoperfusion challenged. J Trauma 2011, 70:765-766

36. Chandler WL, Ferrell C, Trimble S, Moody S: Development of a rapid emergency hemorrhage panel. Transfusion 2010, 50:2547-2552.

37. Yuan S, Ferrell C, Chandler WL: Comparing the prothrombin time INR versus the APTT to evaluate the coagulopathy of acute trauma. Thromb Res 2007, 120:29-37.

38. Amukele TK, Ferrell C, Chandler WL: Comparison of plasma with whole blood prothrombin time and fibrinogen on the same instrument. Am J Clin Pathol 2010, 133:550-556.

39. Kashuk JL, Moore EE, Sabel A, Barnett C, Haenel J, Le T, Pezold M, Lawrence J Biff WL, Cothren CC, Johnson JL: Rapid thrombelastography (r-TEG) identifies hypercoagulability and predicts thromboembolic events in surgical patients. Surgery 2009, 146:764-772; discussion 772-774.

40. Gonzalez E, Pieracci FM, Moore EE, Kashuk JL: Coagulation abnormalities in the trauma patient: the role of point-of-care thromboelastography. Semin Thromb Hemost 2010, 36:723-737.

41. Kashuk JL, Moore EE, Sawyer M, Le T, Johnson J, Biffl WL, Cothren CC, Barnett C, Stahel P, Sillman CC, Sauaia A, Banerjee A: Postinjury coagulopathy management: goal directed resuscitation via POC thrombelastography. Ann Surg 2010, 251:604-614.

42. Schochl H, Voelckel W, Solomon C: Detection and impact of hyperfibrinolysis in trauma. Wien Klin Wochenschr 2010, 122(Suppl 5):S11-S13.

43. Leemann H, Lustenberger T, Talving P, Kobayashi L, Bukur M, Brenni M, Bruesch M, Spahn DR, Keel MJ: The role of rotation thromboelastometry in early prediction of massive transfusion. J Trauma 2010, 69:1403-1408; discussion 1408-1409.

44. Greer SE, Rhynhart KK, Gupta R, Corwin HL: New developments in massive transfusion in trauma. Curr Opin Anaesthesio/ 2010, 23:246-250.

45. Carroll RC, Craft RM, Langdon RJ, Clanton CR, Snider CC, Wellons DD, Dakin PA, Lawson CM, Enderson BL, Kurek SJ: Early evaluation of acute traumatic coagulopathy by thrombelastography. Trans/ Res 2009, 154:34-39.

46. Schochl H, Nienaber U, Maegele M, Hochleitner G, Primavesi F, Steitz B, Arndt C, Hanke A, Voelckel W, Solomon C: Transfusion in trauma: thromboelastometry-guided coagulation factor concentrate-based therapy versus standard fresh frozen plasma-based therapy. Crit Care 2011, 15:R83.

47. Schochl H, Nienaber U, Hofer G, Voelckel W, Jambor C, Scharbert G, KozekLangenecker S, Solomon C: Goal-directed coagulation management of major trauma patients using thromboelastometry (ROTEM)-guided administration of fibrinogen concentrate and prothrombin complex concentrate. Crit Care 2010, 14:R55.

48. Johansson PI, Stissing T, Bochsen L, Ostrowski SR: Thrombelastography and tromboelastometry in assessing coagulopathy in trauma. Scand J Trauma Resusc Emerg Med 2009, 17:45-53.

49. Rugeri L, Levrat A, David JS, Delecroix E, Floccard B, Gros A, Allaouchiche B, Negrier C: Diagnosis of early coagulation abnormalities in trauma patients by rotation thrombelastography. J Thromb Haemost 2007, 5:289-295.

50. Afshari A, Wikkelso A, Brok J, Moller AM, Wetterslev J: Thrombelastography (TEG) or thromboelastometry (ROTEM) to monitor haemotherapy versus usual care in patients with massive transfusion. Cochrane Database Syst Rev 2011, 3:CD007871.

51. Miller TR, Levy DT: Cost-outcome analysis in injury prevention and control: eighty-four recent estimates for the United States. Med Care 2000, 38:562-582.

52. Derrick AJ, Faucher LD: Motorcycle helmets and rider safety: a legislative crisis. J Public Health Policy 2009, 30:226-242.

53. Canadian Institute for Health Information. National Trauma Registry 2011 Report: Hospitalizations for Major Injury in Canada, Toronto [www.cihi.ca/ntr]

54. Public Health Agency of Canada. Leading Causes of Death and Hospitalization in Canada [http://www.phac-aspc.gc.ca/publicat/lcd-pcd97/ index-eng.php]

55. Macdonald S, Wells S, Giesbrecht N, Cherpitel CJ: Demographic and substance use factors related to violent and accidental injuries: results from an emergency room study. Drug Alcohol Depend 1999, 55:53-61.

56. Haut ER, Kalish BT, Cotton BA, Efron DT, Haider AH, Stevens KA, Kieninger AN, Cornwell EE, 3rd, Chang DC: Prehospital intravenous fluid administration is associated with higher mortality in trauma patients: a National Trauma Data Bank analysis. Ann Surg 2011, 253:371-377.

57. Mock C: Strengthening care for the injured globally. J Trauma 2011 70:1307-1316

58. Hameed SM, Schuurman N, RazekT, Boone D, Van Heest R, Taulu T, Lakha N, Evans DC, Brown DR, Kirkpatrick AW, Stelfox HT, Dyer D, van WijngaardenStephens M, Logsetty S, Nathens AB, Charyk-Stewart T, Rizoli S, Tremblay LN, Brenneman F, Ahmed N, Galbraith E, Parry N, Girotti MJ, Pagliarello G, Tze N, Khwaja K, Yanchar N, Tallon JM, Trenholm JA, Tegart C, Amram O, Berube M, Hameed U, Simons RK; Research Committee of the Trauma Association of Canada: Access to trauma systems in Canada. J Trauma 2010, 69:1350-1361; discussion 1361

59. Minei JP, Schmicker RH, Kerby JD, Stiell IG, Schreiber MA, Bulger E, Tisherman S, Hoyt DB, Nichol G: Severe traumatic injury: regional variation in 
incidence and outcome. Ann Surg 2010, 252:149-157.

60. Tien HC, Spencer F, Tremblay LN, Rizoli SB, Brenneman FD: Preventable deaths from hemorrhage at a level I Canadian trauma center. J Trauma 2007, 62:142-146.

61. Huber-Wagner S, Qvick M, MussackT, Euler E, Kay MV, Mutschler W, Kanz KG Massive blood transfusion and outcome in 1062 polytrauma patients: a prospective study based on the Trauma Registry of the German Trauma Society. Vox Sang 2007, 92:69-78.

62. Hodgetts TJ, Mahoney PF: Military pre-hospital care: why is it different? J RArmy Med Corps 2009, 155:4-8.

63. Mabry R, McManus JG: Prehospital advances in the management of severe penetrating trauma. Crit Care Med 2008, 36:S258-S266.

64. Rossaint R, Bouillon B, Cerny V, Coats TJ, Duranteau J, Fernández-Mondéjar E, Hunt BJ, Komadina R, Nardi G, Neugebauer E, Ozier Y, Riddez L, Schultz A, Stahel PF, Vincent JL, Spahn DR; Task Force for Advanced Bleeding Care in Trauma: Management of bleeding following major trauma: an updated European guideline. Crit Care 2010, 14:R52.

65. Thomas D, Wee M, Clyburn P, Walker I, Brohi K, Collins P, Doughty H, Isaac J, Mahoney PM, Shewry L: Blood transfusion and the anaesthetist: management of massive haemorrhage. Anaesthesia 2010, 65:1153-1161.

66. Napolitano LM, Kurek S, Luchette FA, Anderson GL, Bard MR, Bromberg W, Chiu WC, Cipolle MD, Clancy KD, Diebel L, Hoff WS, Hughes KM, Munshi I, Nayduch D, Sandhu R, Yelon JA, Corwin HL, Barie PS, Tisherman SA, Hebert PC; EAST Practice Management Workgroup; American College of Critical Care Medicine (ACCM) Taskforce of the Society of Critical Care Medicine (SCCM): Clinical practice guideline: red blood cell transfusion in adult trauma and critical care. J Trauma 2009, 67:1439-1442.

67. American College of Surgeons. Committe on Trauma: Advanced Trauma Life Support [http://www.facs.org/trauma/index.html]

68. Kirkpatrick AW, Ball CG, D'Amours SK, Zygun D: Acute resuscitation of the unstable adult trauma patient: bedside diagnosis and therapy. Can J Surg 2008, 51:57-69.

69. Lippi G, Ippolito L, Cervellin G: Disseminated intravascular coagulation in burn injury. Semin Thromb Hemost 2010, 36:429-436.

70. Hardy JF, De Moerloose P, Samama M: Massive transfusion and coagulopathy: pathophysiology and implications for clinical management. Can J Anaesth 2004, 51:293-310.

71. Guerriero C, Cairns J, Perel P, Shakur H, Roberts I: Cost-effectiveness analysis of administering tranexamic acid to bleeding trauma patients using evidence from the CRASH-2 trial. PLOS ONE 2011, 6:e18987.

72. Stanworth SJ, Birchall J, Doree CJ, Hyde C: Recombinant factor VIla for the prevention and treatment of bleeding in patients without haemophilia. Cochrane Database Syst Rev 2007, 2:CD005011.

73. Lin Y, Stanworth S, Birchall J, Doree C, Hyde C: Recombinant factor Vlla for the prevention and treatment of bleeding in patients without haemophilia. Cochrane Database Syst Rev 2011, 2:CD005011.

74. Avorn J, Kesselheim A: A hemorrhage of off-label use. Ann Intern Med 2011 , 154:566-567.

75. Davenport R, Curry N, Manson J, De'Ath H, Coates A, Rourke C, Pearse R,
Stanworth S, Brohi K: Hemostatic effects of fresh frozen plasma may be maximal at red cell ratios of 1:2. J Trauma 2011, 70:90-95; discussion 95-96.

76. Inaba K, Branco BC, Rhee P, Blackbourne LH, Holcomb JB, Teixeira PG, Shulman I, Nelson J, Demetriades D: Impact of plasma transfusion in trauma patients who do not require massive transfusion. J Am Coll Surg 2010, 210:957-965.

77. Chaiwat O, Lang JD, Vavilala MS, Wang J, MacKenzie EJ, Jurkovich GJ, Rivara FP: Early packed red blood cell transfusion and acute respiratory distress syndrome after trauma. Anesthesiology 2009, 110:351-360.

78. Borgman MA, Spinella PC, Holcomb JB, Blackbourne LH, Wade CE, Lefering R, Bouillon B, Maegele M: The effect of FFP:RBC ratio on morbidity and mortality in trauma patients based on transfusion prediction score. Vox Sang 2011, 101:44-54.

79. Murthi SB, Dutton RP, Edelman BB, Scalea TM, Hess JR: Transfusion medicine in trauma patients. Expert Rev Hematol 2008, 1:99-109.

80. Flower $\mathrm{O}, \mathrm{Smith} \mathrm{M}$ : The acute management of intracerebral hemorrhage. Curr Opin Crit Care 2011, 17:106-114.

81. Downey DM, Monson B, Butler KL, Fortuna GR, Jr, Saxe JM, Dolan JP, Markert RJ, MCCarthy MC: Does platelet administration affect mortality in elderly head-injured patients taking antiplatelet medications? Am Surg 2009, 75:1100-1103.

82. Creutzfeldt CJ, Weinstein JR, Longstreth WT, Jr, Becker KJ, McPharlin TO, Tirschwell DL: Prior antiplatelet therapy, platelet infusion therapy, and outcome after intracerebral hemorrhage. J Stroke Cerebrovasc Dis 2009, 18:221-228.

83. Ducruet AF, Hickman ZL, Zacharia BE, Grobelny BT, DeRosa PA, Landes E, Lei S, Khandij J, Gutbrod S, Connolly ES, Jr: Impact of platelet transfusion on hematoma expansion in patients receiving antiplatelet agents before intracerebral hemorrhage. Neurol Res 2010, 32:706-710.

84. Simons R, Brasher P, Taulu T, Lakha N, Molnar N, Caron N, Schuurman N, Evans D, Hameed M: A population-based analysis of injury-related deaths and access to trauma care in rural-remote Northwest British Columbia. J Trauma 2010, 69:11-19.

85. Davenport RA, Tai N, West A, Bouamra O, Aylwin C, Woodford M, McGinley A, Lecky F, Walsh MS, Brohi K: A major trauma centre is a specialty hospital not a hospital of specialties. Br J Surg 2010, 97:109-117.

86. MacKenzie EJ, Rivara FP, Jurkovich GJ, Nathens AB, Frey KP, Egleston BL, Salkever DS, Scharfstein DO: A national evaluation of the effect of traumacenter care on mortality. N Engl J Med 2006, 354:366-378.

87. Twijnstra MJ, Moons KG, Simmermacher RK, Leenen LP: Regional trauma system reduces mortality and changes admission rates: a before and after study. Ann Surg 2010, 251:339-343.

doi:10.1186/cc10498

Cite this article as: Dzik WH, et al:: Clinical review: Canadian National Advisory Committee on Blood and Blood Products - Massive Transfusion Consensus Conference 2011: report of the panel. Critical Care 2011, 15:242. 